\title{
A new approach for strawberry disease control
}

\author{
F. Takeda ${ }^{1}$, W.J. Janisiewicz ${ }^{1}$, B.J. Smith ${ }^{2}$ and B. Nichols ${ }^{1}$ \\ ${ }^{1}$ USDA Agricultural Research Service, Appalachian Fruit Research Station, 2217 Wiltshire Road, Kearneysville, WV 25430, \\ USA \\ ${ }^{2}$ USDA Agricultural Research Service, Thad Cochran Southern Horticultural Laboratory, 810 Highway 26, Poplarville, \\ MS 39470, USA
}

\section{Summary}

Ultraviolet-C (UV-C) irradiation has been used on small scale to kill microorganisms in agriculture and for control of foodborne pathogens in food industries. However, the doses of UV-C $(254 \mathrm{~nm})$ irradiation required to reduce diseases on strawberry and other plants have caused phytotoxicity. Here we report a new approach demonstrating greater killing power of UV-C irradiation against fungal pathogens without damaging strawberry plants when UV-C treatment was followed by a specific dark period. Field trials also included applications of microbial antagonists twice a week. The dark period most likely prevented activation of the light-induced DNA repair mechanism in microorganisms and greatly increased the lethality of the UV-C. This approach allowed for a substantial reduction of the UV-C effective dose to kill the microorganisms on leaves, flowers and fruit, without damaging the strawberry plant. The application of microbial antagonists resulted in excellent colonization of strawberry plants which filled the microbial void after UV-C "sterilization" and provided a barrier for recolonization by plant and potential foodborne pathogens.

Keywords

anthracnose, Aureobasidium, biological control, Botrytis, Colletotrichum, Fragaria $\times$ ananassa, fruit rot, gray mold, Metschnikowia, powdery mildew, ultraviolet-C

\section{Introduction}

Strawberry is grown in various production systems under diverse environmental conditions making fruit available year-round in many parts of the world. The different production conditions create challenges in controlling fruit pathogens such as gray mold (caused by B. cinerea), anthracnose (caused by Colletotrichum spp.), and powdery mildew (caused by P. aphanis) during production and after harvest. Currently, growers in California depend on as many as 20 fungicide applications to control these diseases (Strand, 2008) each year from pre-anthesis to harvest. In a conventional production system, it is critical that fungicide applications begin in the field prior to bloom to protect flowers because infection at this stage accounts for as much as $80 \%$ of fruit decay at and after harvest (Bulger et al., 1987). However, there are reports showing frequent fungicide applications lead to development of resistance in targeted and non-targeted fungal pathogens (Kretschmer et al., 2009; Oliveira et al., 2017). The development of resistance to fungicides in

\section{Significance of this study}

What is already known on this subject?

- Ultraviolet-B (UV-B) and ultraviolet-C (UV-C) irradiation treatments of strawberries were reported to reduce disease incidence, but often damaged plants at the doses required to kill or reduce pathogens.

What are the new findings?

- Non-chemical control of several fungal pathogens of strawberry was developed. UV-C irradiation followed by a dark period controlled strawberry diseases and applications of microbial antagonists reduced recolonization of strawberry leaves and fruit by fungal pathogens.

What is the expected impact on horticulture?

- The research has implications for non-chemical disease management strategies (e.g., night-time UV-C irradiation and application of microbial antagonists) and circumventing development of fungicide resistance by pathogens.

major pathogens makes chemical control of diseases unsustainable (Oliveira et al., 2017). In the United States, recently many isolates of $B$. cinerea obtained from grower fields in the Southeast (Fernandez-Ortuno et al., 2015) and California (Pokorny et al., 2016) were found to be resistant to commonly used fungicides (e.g., fenhexamid, thiophanate-methyl, boscalid, pyraclostrobin, and iprodione). To combat development of resistance, strawberry growers are recommended to use fungicide resistant management strategies (e.g., rotation of fungicides in conjunction with cultural practices aimed at reducing plant moisture and pathogen inoculum levels). In Florida, growers are encouraged to use disease prediction models to reduce the number of fungicide applications (Pavan et al., 2012).

Ultraviolet (UV-C) irradiation has been used to kill microorganisms in various strawberry production systems. In Belgium, Van Delm et al. (2014) demonstrated the killing power of UV-C on powdery mildew fungus and other fungal pathogens in glasshouse strawberry system. In Japan, Kanto et al. (2009) reported the promotion of resistance induction in strawberry plants against fungal pathogens by UV-B radiation. However, the UV technology in strawberry cultivation has been limited due to its damaging effect to plants at the doses required to kill or reduce pathogen populations. Recently, a higher microbial (e.g., B. cinerea and P. aphanis) killing power without damaging the strawberry plant was achieved with night-time UV-C irradiation followed by a dark period (Janisiewicz et al., 2016a, b). UV-C irradiation also 
has been shown to effect plant growth and development. UV-C treatments on greenhouse-grown ornamental crops increased shoot branching and number of flowers and accelerated or delayed flowering time depending on the exposure time and dosage (Bridgen, 2016; Darras et al., 2013).

The success of modern strawberry production systems has come largely from development of superior cultivars, increased use of petro-chemical products (e.g., fertilizers, insecticides, fungicides) and increasing the area of cultivated land. The challenge facing strawberry growers is to maintain production without putting more demands for chemicals for plant health as well as to discover how to maintain yield and quality by sustainable production methods. Control of strawberry diseases is among the most significant aspects still remaining for increasing fruit production; and non-chemical approaches including biological control meets this goal in a way that is sustainable (Cook and Baker, 1983). Effective biological control approaches should suppress or kill pathogen inoculum or protect plants against infection so that chemical use is minimized or possibly eliminated (Burr et al., 1978). Today, more consumers are demanding fruit free of pesticide residues and the organic strawberry market is rapidly growing (Dimitri and Greene, 2002). Several attempts to control strawberry diseases with organic compliant microbial antagonists revealed the potential and the limitation of the biological control approach (Sylla et al., 2013). Thus, combining biological control with the non-fungicide aspects of the IPM system and any new compatible alternative control method appears to be a logical, sustainable, and more effective approach (Janisiewicz and Conway, 2011).

Here we report on investigation of the effect of night time UV-C treatments on two species of Colletotrichum, fruit production profile in 'Chandler' strawberry, and season-long night-time UV-C irradiation combined with application of microbial antagonists for effective colonization of 'Monterey' strawberry plants after UV-C treatment in a semi-protected environment.

\section{Materials and methods}

All in vitro and in vivo studies, unless otherwise indicated, were performed from 2011 to 2017 at the Appalachian Fruit Research Station, Kearneysville, WV, USA.

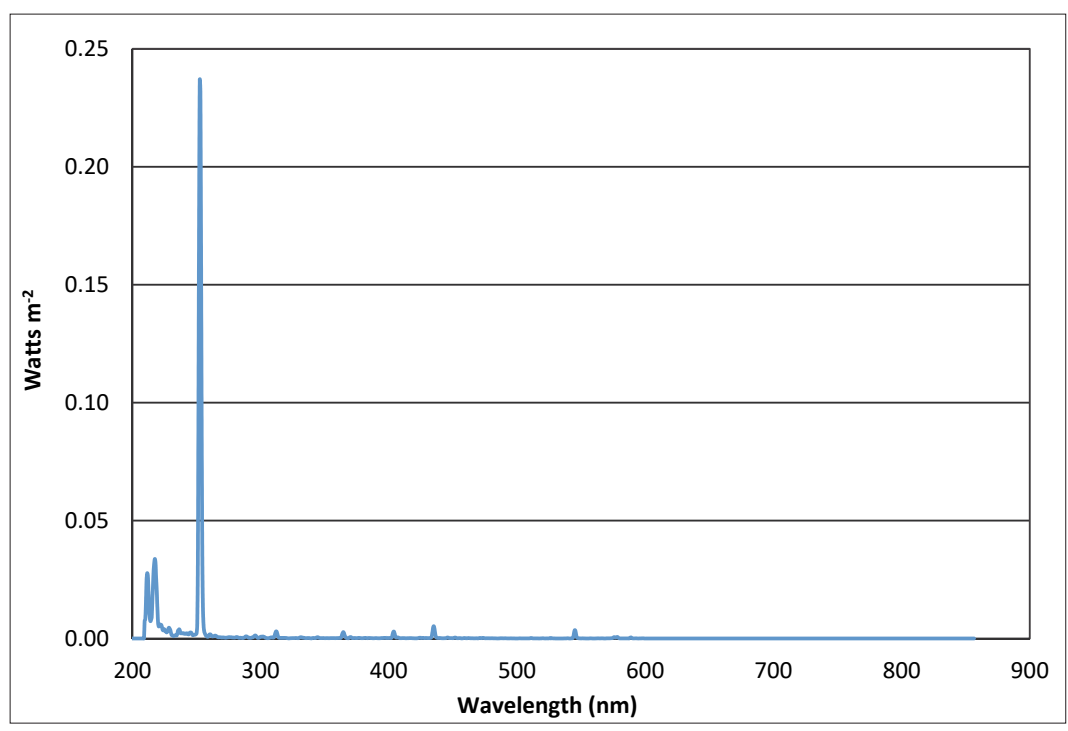

FIGURE 1. Spectral discharge $\left(\mathrm{W} \mathrm{m}^{-2}\right)$ from a $55-\mathrm{W}$ UV-C lamp captured with a StellarNet spectrometer. The tip of the fiber optic cable was positioned at a distance of $30 \mathrm{~cm}$ directly underneath the lamp.

\section{Ultraviolet lamp}

UV-C lamps [55 W, Philips Model TUVPL-L 55/HF (Philips North America Corp., Andover, MA, USA)] in an electronically brightened reflector surface housing were obtained from CureUV.com (Delray Beach, FL, USA). Spectral analysis was performed with a UV-VIS StellarNet spectrometer (Model EPP2000C, StellarNet, Inc., Tampa, FL, USA), with a resolution of $0.1 \mathrm{~nm}$. The end of a multimode fiber optic cable (Model F400, StellarNet, Inc., Tampa, FL, USA) was positioned at a distance of $30 \mathrm{~cm}$ and pointed toward the lamp. The spectral information was acquired with the SpectraWiz spectrometer software and the data were displayed using the Microsoft Excel spreadsheet (Figure 1).

\section{Anthracnose study (C. acutatum, C. fragariae, and C. gloeosporioides)}

Conidial suspension of $C$. acutatum adjusted to $1 \times 10^{4}$ conidia $\mathrm{mL}^{-1}$ was vortexed thoroughly and an aliquot of $100 \mu \mathrm{L}$ was spread onto $10 \mathrm{~cm}$ potato dextrose agar (PDA) plates. Plates were placed on a tray and after $20 \mathrm{~min}$, the lids from the plates were removed and the tray was placed under UV-C light at a distance of $30 \mathrm{~cm}$. The plates were removed after exposure to UV-C for $15,30,45$, or $60 \mathrm{sec}$, the lids were placed back on the plates, and the plates were sealed with Parafilm and either placed immediately in light or incubated in dark for $4 \mathrm{~h}$ before exposing to continuous light at $25^{\circ} \mathrm{C}$. The number of colonies that emerged were counted after 3 , 6 , and 10 days of incubation. There were three replicates of individual plates per treatment and the experiment was repeated.

Two studies were conducted at USDA-ARS Thad Cochran Southern Horticultural Laboratory (TCSHL) located in Poplarville, MS. In one study, three $10-\mu \mathrm{L}$ drops of conidial suspension of $C$. gloeosporioides isolate CG-162 $\left(1 \times 10^{4}\right.$ conidia $\mathrm{mL}^{-1}$ ) were placed on PDA plates. The plates were exposed to UV-C light for 30,60 , or $90 \mathrm{sec}$ and then incubated in dark for $0,2,4,6$, or $8 \mathrm{~h}$ before moving the plates under fluorescent lamps. The experiment consisted of three plates for each UV-C exposure time and dark incubation period $(n=60)$. Three, 6 , and 10 days after inoculation fungal colony size was determined by measuring the diameter.

In the second study at TCSHL, detached leaf assay for anthracnose infection was used to determine the effect of UV-C irradiation and dark incubation period on C. fragariae and C. gloeosporioides. 'Chandler' strawberry, a short-day cultivar released in 1984 by the University of California and susceptible to $C$. fragariae and C. gloeosporioides (Chang and Smith, 2007) was used in this study. The transplants were purchased from a commercial nursery (Lassen Canyon Nursery, Redding, CA, USA) and established in 10-cm plastic pots in a 1:1 mixture of Jiffy-Mix (Jiffy Products of America Inc., West Chicago, IL, USA) and sand. Plants were maintained in a greenhouse at $28^{\circ} \mathrm{C} \pm 10^{\circ} \mathrm{C}$ with a 16 -h photoperiod.

Detached strawberry leaf (DSL) assay developed for strawberry germplasm screening for anthracnose resistance (Miller-Butler et al., 2013) was used in 2016. Inoculum was prepared as a conidial suspension from 7 - to 14-day-old cultures by flooding each culture plate with sterile 
deionized water and gently scraping the agar surface with a glass rod to remove conidia. The resulting conidial suspension was filtered through one layer of bandage gauze (Johnson and Johnson, New Brunswick, NJ, USA) and adjusted to a concentration of $1.5 \times 10^{6}$ conidia $\mathrm{mL}^{-1}$ using a hemacytometer by diluting with sterile deionized water with $0.05 \%$ Tween 20 (Sigma Chemical Co., St. Louis, MO, USA).

For each replicate, 36 leaves were collected from plants and randomly assigned to treatment. Petioles were inserted into small tubes containing sterile water and placed on racks. The upper surface of leaflets were inoculated with $C$. fragariae (CF-75) or C. gloeosporioides (CG-162) (Smith and Black, 1990 ) by misting with the conidial suspension. Water was misted onto control leaves. Inoculated leaves were incubated in the dark for $20 \mathrm{~h}$ in closed opaque boxes containing about $5 \mathrm{~cm}$ of water at the bottom and were then exposed to UV-C light durations of $0,1,2$, or $3 \mathrm{~min}$. The leaves in the ' $0 \mathrm{~h}$ dark' treatment were placed in clear humidity boxes. The leaves in the ' 4 and $8 \mathrm{~h}$ dark' treatments were placed in opaque humidity boxes. At the end of each dark treatment time, leaves were placed in clear humidity boxes and incubated under light. The Disease Severity Rating (DSR) scale used to evaluate the leaf was: $0=$ no visible disease symptom on any leaflet, 1 through $4=$ increasing disease symptom severity, and $5=$ total area of leaflets necrotic at 3, 6, and 10 days after inoculation (DAI). The experimental design for the DSL study was a completely randomized design. DSR data were square root transformed using square root $(\mathrm{Y}+0.5)$ and analyzed with analysis of variance (ANOVA). If significant differences were found with ANOVA, means were separated based on Fisher's protected least significant difference (SAS, version 9.4; SAS Institute Inc., Cary, NC, USA). The data were back-transformed for presentation.

\section{Fruit production}

Cold stored bare-root transplants of 'Chandler' strawberry, a short-day cultivar, were purchased in early December 2016 from Lassen Canyon Nursery, established in $16.25 \mathrm{~cm}$ (6.5 in) standard TEKU round pots (Pöppelmann GmbH \& Co., Lohne, Germany) filled with PRO-MIX peat-based growing media (Premier Horticulture Ltd., Olds, Alberta, Canada) and maintained on a greenhouse bench. Flowers and runners were removed until January 3, 2017. Twenty-four potted plants were then moved onto shelves located in three walk-in environmental chambers clad with bi-wall acrylic glass. On one of the six shelves a UV-C irradiation apparatus was mounted (Figure 2). The apparatus had 8 GermAway UV disinfection lamps (55 Watt UV-C lamps, Philips Model TUV PL-L 55/HF, CureUV, Delray Beach, FL, USA) installed with an electronically brightened reflector surface housing. Four lamps were positioned above and four lamps below plant height along the side of plant row. Top lamps were $30 \mathrm{~cm}$ away from the plants and angled downward. The bottom lamps were $30 \mathrm{~cm}$ away from the plants and angled up to the plants. Plants were set $30 \mathrm{~cm}$ apart in a row on the shelf. The irradiation intensity at the top of the plant $(\sim 30 \mathrm{~cm}$ distance from the lamps) was $0.206 \mathrm{~W} \mathrm{~m}^{-2}$. Thus, the $60 \mathrm{~s}$ illumination corresponded to $12 \mathrm{~J} \mathrm{~m}^{-2}$.

Strawberry plants were irradiated at 3-day intervals. UV-C lamps were programmed to turn on for $60 \mathrm{~s}$ at 10:00 pm. The shelves with 4 control plants (no UV-C treatment) were separated by a black fleece fabric late in the afternoon prior to light treatment to prevent these plants from receiving any UV-C irradiation. The fabric was pulled back the following morning.
Mature strawberries were harvested at 3- to 4-day intervals as they ripened, beginning in early February for 32 days. At each harvest, fruit were counted, weighed, and visually assessed for powdery mildew infection. The experiment consisted of three groups of four plants and two treatments (UV-C irradiation treatment and no UV-C exposure). Each treatment was replicated 4 times in a completely randomized block design. The data were analyzed using Proc GLM and the means were separated using Student's $t$ test by SAS/ STAT 14.1 (SAS Institute Inc., Cary, NC, USA).

\section{Biocontrol tests on strawberry petals}

Flower petal test was developed to determine the effect of microbial antagonist application on petal infection by B. cinerea. Strawberry flowers were harvested from 'Chandler' plants in greenhouse culture. The petals were detached from flowers and placed on glass microscope slides in a petri dish with moistened filter paper. In all, 12 petri dishes were prepared for the test ( $n=48$ petals). To each petal, a drop of $B$. cinerea suspension $\left(1 \times 10^{5}\right.$ conidia $\left.\mathrm{mL}^{-1}\right)$ alone or in combination with antagonist suspensions of Metschnikowia pulcherrima or Aureobasidium pullulans (concentrations adjusted to $50 \% \mathrm{~T}$ at $420 \mathrm{~nm}$ with a spectrophotometer) was placed using a pipette. Each treatment (petri dish) was replicated 4 times and set up in completely randomized design. The data were analyzed using Proc GLM and the means were separated by Duncan-Waller multiple range test using SAS/ STAT 14.1 (SAS Institute Inc., Cary, NC, USA).

\section{Effect of UV-C on populations of the applied antagonists on strawberries}

Strawberry 'Monterey', a day-neutral cultivar released in 2009 by the University of California, was used in the study. Plants were purchased from a commercial nursery (Lassen Canyon Nursery) in November 2016. They were transplanted into $16.25 \mathrm{~cm}$ (6.5 in) standard TEKU round pots (Pöppelmann GmbH \& Co., Lohne, Germany) filled with PRO-MIX peat-based growing media (Premier Horticulture Ltd., Olds, Alberta, Canada) and maintained on a bench in a heated greenhouse. Monthly applications of $20 \mathrm{~g}$ Scotts Osmocote Plus slow-release fertilizer (Scotts Brands, Marysville, $\mathrm{OH}$, USA), supplemented with $0.1 \mathrm{~g}$ of iron chelate Sprint 138 (6\% Fe, BASF, Ludwigshafen, Germany). Plants were maintained in a heated greenhouse, watered as needed, and flowers and runners removed at 2-week intervals. Insecticides and miticides were applied as recommended in a commercial strawberry production guide (Demchak, 2013).

In 2017 'Monterey' strawberry plants were moved from the greenhouse in late April and placed in 4 rows of raised beds in a single-bay high tunnel (Ledgewood Farm, Moultonborough, NH, USA). The raised beds were covered with a reflective aluminized (silver-over-black) mulch film (Filmtech, Bean Station, TN, USA). Four pots were inserted through a hole cut out $30-\mathrm{cm}$ apart in the mulch (Figure 3). Treatments were randomized within replication blocks among the 4 rows. UV-C treatment and antagonist application were carried out between May and July for 11 weeks. Rows 1 and 3 were treated with UV-C $(254 \mathrm{~nm})$ between 10:00 and 11:00 pm on Monday and Thursday. Each plot in rows 1 and 3 received $60 \mathrm{~s}$ irradiation $\left(12.36 \mathrm{~J} \mathrm{~m}^{-2}\right)$ while pots in rows 2 and 4 were not treated with UV-C. Each row contained 3 replications of different treatments (control no spray, antagonists A1 A. pullulans, A2 M. pulcherrima, and A1 plus A2). The antagonists were freshly prepared before each application by growing cultures in 500-mL Erlenmeyer flasks containing 


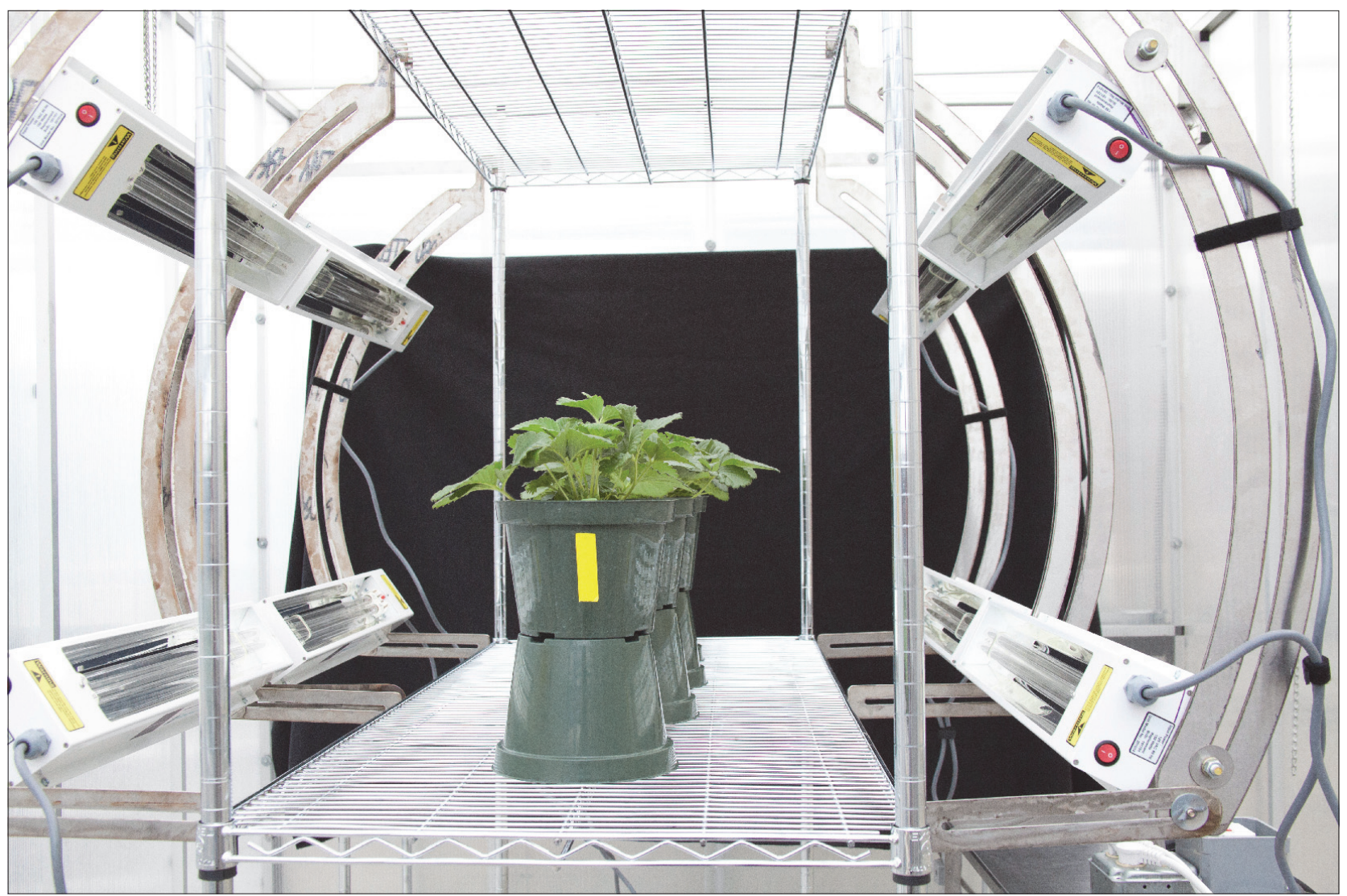

FIGURE 2. Stationary UV-C irradiation apparatus for treatment of strawberry plants. Eight UV-C lamps (55 W; CureUV.com, Delray Beach, FL, USA) were mounted on the rack. Two top light fixures were angled down toward the plant and the two lower light fixures were positioned below plant height and angled upward.

$200 \mathrm{~mL}$ of nutrient yeast dextrose broth (NYDB) medium on a rotary shaker at $26^{\circ} \mathrm{C}$ for $24 \mathrm{~h}$. On the day of application the cultures were harvested by centrifugation at 7,000 $\mathrm{g}$ for $10 \mathrm{~min}$, the pelleted cells were re-suspended in sterile tap water and the concentrations were adjusted with a spectrophotometer to $30 \% \mathrm{~T}$ at $420 \mathrm{~nm}$. The antagonist treatments were applied to designated treatment plots using a 4-L hand sprayer to runoff the morning after night-time UV-C treatment.

Leaf samples, consisting of three leaves per plot, were collected at the end of the experiment in late July. Fruit samples $\left(\sim 50\right.$ g plot $\left.^{-1}\right)$ were collected at the same time. Leaf (total of 9 leaflets per plot) and fruit samples were placed in separate beakers with 200 and $100 \mathrm{~mL}$ sterile water, respectively. The beakers were sonicated for $60 \mathrm{sec}$ in Branson 1510 sonication bath with output of $70 \mathrm{~W}$ and $42 \mathrm{kHz}$ (Branson Ultrasonic Corp., Danbury, CT, USA) and placed on a rotary shaker (150 rpm) for $10 \mathrm{~min}$ to facilitate washing of the microorganisms from leaf and fruit surfaces. One hundred $\mathrm{mL}$ of two ten-fold-dilutions of the original washings were plated on $10-\mathrm{cm}$ diameter petri plates containing NYDA medium with streptomycin $\left(100 \mathrm{mg} \mathrm{L}^{-1}\right)$ and penicillin $\left(80 \mathrm{mg} \mathrm{L}^{-1}\right)$. The plates were incubated at $25^{\circ} \mathrm{C}$ for 3 days and then colony forming units were visually counted and data were recorded for each plate. The experiment was a randomized complete block design with tissue samples collected from 3 treatment plots. In addition, $100 \mu \mathrm{L}$ of undiluted, original washings were plated for photographic data acquisition. The effect of UV-C treatment on microbial antagonist populations was analyzed as a one-factor liner model using a Student's $t$-test.

\section{UV-C irradiation apparatus in high tunnel}

The apparatus for UV-C irradiation treatment was a mobile tricycle-type (e.g., one wheel in the front and two in the back) vehicle that moved over four elevated plant beds (Figure 4). The three wheels were positioned to align with the center of each aisle. A steering and drive mechanism was mounted adjacent to the front wheel. The steering mechanism consisted of a pair of roller assemblies extending laterally from the front wheel to a vertical wall portion of the elevated plant bed. The roller assemblies maintain the front wheel centered in the aisle. Four UV-C light arrays were attached to the platform and aligned with the plant rows (Figure 4). The forward movement of the treatment apparatus was controlled by a programmable electronic controller. The controller coordinated electronic signals both to and from the UV-C light array assembly and the steering and drive mechanism to cover predetermined distances. When the apparatus moved over a plot of strawberry plants, a sequence of commands was initiated to stop the forward movement of the apparatus, begin light treatment for specified rows for a preset time (e.g., $60 \mathrm{~s}$ ). After the light turned off the apparatus was programmed to move forward until it reached the next section, at which time another set of pre-programmed light treatment was initiated to illuminate the selected rows. This sequence of events was repeated for the third, fourth, and fifth sections. The following morning, the apparatus was manually pushed back to its original position next to section 1 . 


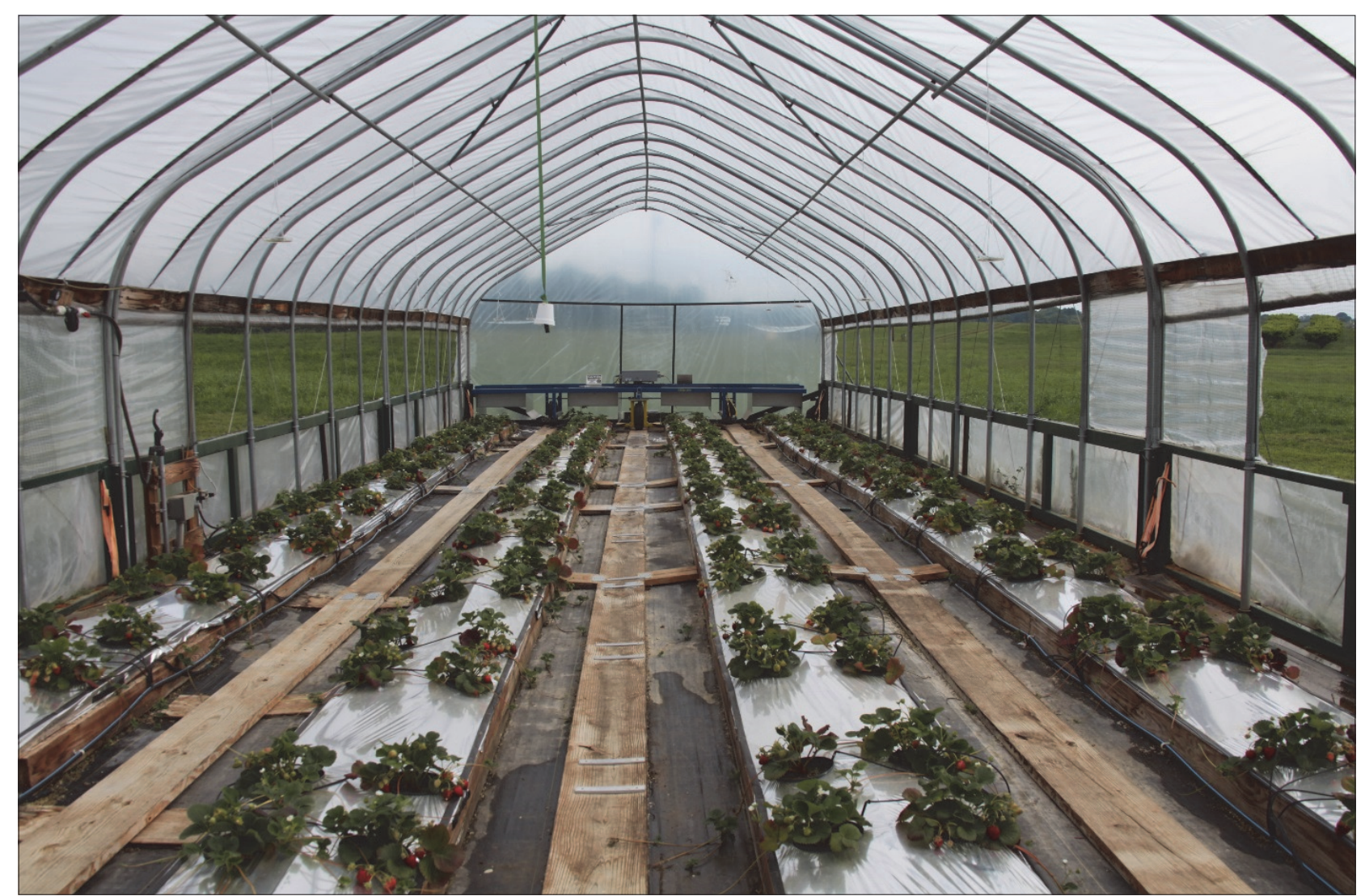

FIGURE 3. The high tunnel complex located at the Appalachian Fruit Research Station in which the analysis of microbial antagonist survival and fungal abundance on strawberry leaves and fruit was performed. Four raised beds were constructed and covered with aluminized plastic mulch. Each plot within a row consisted of 4 potted 'Monterey' plants spaced $30 \mathrm{~cm}$ apart. The UV-C apparatus is located at the back of the tunnel against the wall.

\section{Results}

\section{Effect of UV-C treatment and incubation in the dark on Colletotrichum species}

No visible $C$. acutatum colonies were observed on PDA plates after 1 day of incubation. Irradiation of the C. acutatum conidia with UV-C with no subsequent dark period required $45 \mathrm{~s}$ or more exposure time to reduce conidia viability and colony development (Figure 5). However, when irradiated conidia from the same experiment were subjected to a 4-hour dark period immediately after irradiation before exposure to continuous incandescent light, partial inhibition of germination and development of the colonies was achieved with just $15 \mathrm{~s}$ UV-C irradiation as indicated by fewer and small diameter fungal colonies. The majority of plates showed no colony development when exposed to $30 \mathrm{~s}$ or longer periods to UV-C irradiation, followed by 4-hour dark incubation time. A slightly different method was used to test the susceptibility of $C$. gloeosporioides to UV-C irradiation, but the results were similar to those obtained from tests with $C$. acutatum. As the exposure time was increased, reduction in colony growth was greater (Figure 6). Complete colony inhibition was achieved with $90 \mathrm{~s}$ UV-C irradiation. At least $60 \mathrm{~s} \mathrm{UV-C}$ irradiation was necessary to reduce the number of colonies. The results clearly showed that increasing the dark period subsequent to UV-C light irradiation was an effective method to enhance efficacy of UV-C irradiation in killing $C$. acutatum and $C$. gloeosporioides.

In the detached leaf assay, significant differences in the DSR scores were obtained due to Colletotrichum isolates, isolate $\times$ study interaction, and UV-C exposure time (Table 1). Disease severity scores 3,6 , and 10 days after inoculation of

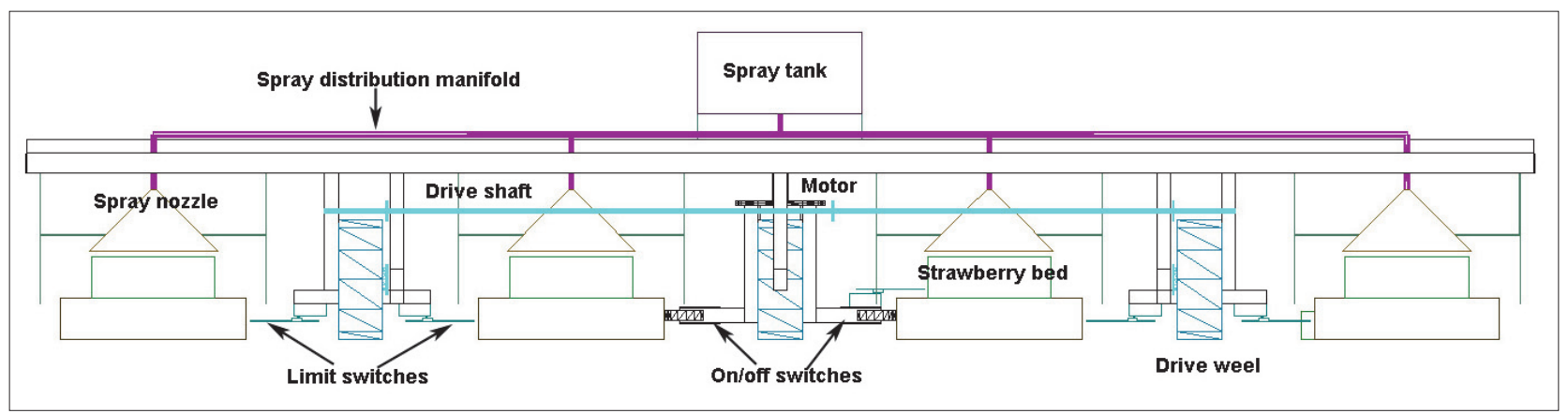

FIGURE 4. The front view of the USDA mobile, programmable 4-row strawberry bed UV-C application platform. 


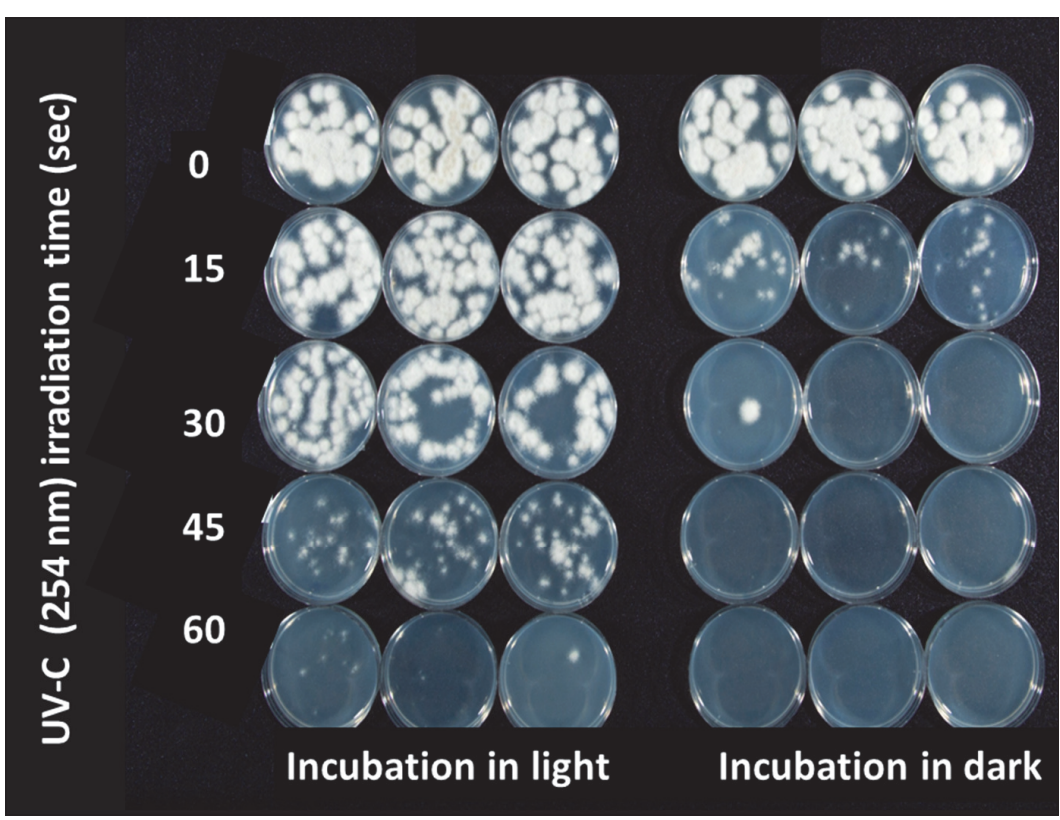

FigURE 5. Effect of UV-C exposure time $(0$, $15,30,45$, and $60 \mathrm{sec}$ ) and subsequent incubation either in light or in dark for $4 \mathrm{~h}$ and then returned to light on growth of Colletotrichum acutatum after 4-day incubation. One hundred $\mu \mathrm{L}$ aliquot $\left(1 \times 10^{4}\right.$ conidia $\left.\mathrm{mL}^{-1}\right)$ was spread on each PDA plate. The plates with the lids removed were exposed to UV-C light after suspension was completely absorbed into the media. leaves inoculated with $C$. fragariae $(0.58,1.44$, and 2.05 , respectively) were higher than scores of leaves inoculated with C. gloeosporioides $(0.48,1.02$, and 1.67 , respectively). Since there was a significant study $\times$ isolate effect, the data from the two studies were combined and analyzed by isolate. At 3 DAI, all leaves were rated $<1$, however, leaves inoculated with $C$. fragariae and incubated in the dark for $4 \mathrm{~h}$ after UV-C exposure had slightly higher disease severity scores (0.8) than leaves incubated in the dark for 0 or $8 \mathrm{~h}(0.4$ and 0.5 , respectively). At $6 \mathrm{DAI}$, leaf necrosis had increased to near 2 DSR score, and leaves incubated in the dark for $4 \mathrm{~h}$ had significantly higher scores (1.8) than those incubated in the dark for $0 \mathrm{~h}$ (1.3). After 10 days there was not a significant difference in leaf disease severity scores among the three dark treatments.

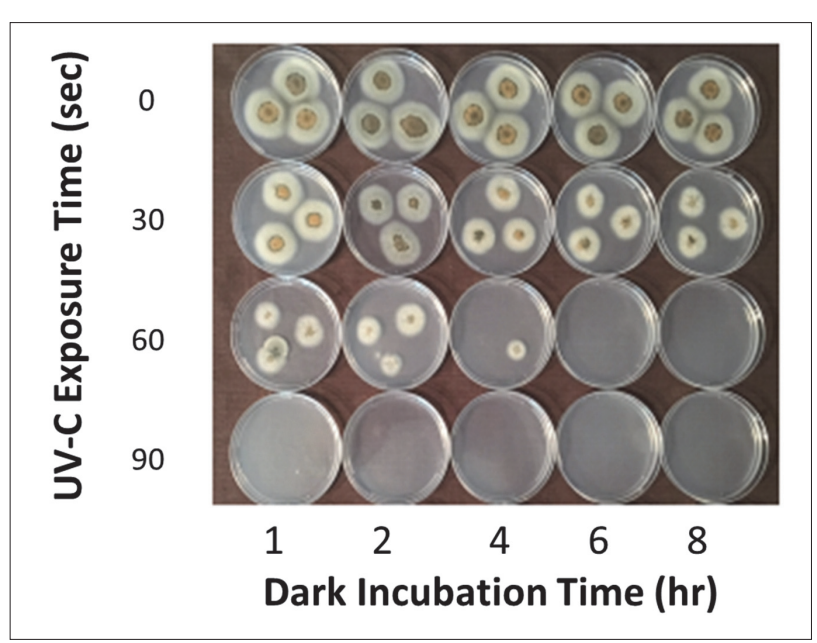

FigurE 6. Effect of UV-C exposure time $(0,30,60$, and $90 \mathrm{sec})$ and subsequent dark incubation period $(0,2,4,6$, and $8 \mathrm{~h})$ on growth of Colletotrichum gloeosporioides isolate CG162 after 4-day incubation. Three $10 \mu \mathrm{L}$ drops $\left(1 \times 10^{4}\right.$ conidia $\left.\mathrm{mL}^{-1}\right)$ were placed on each PDA plate. The plates with the lids removed were exposed to UV-C light after drops were completely absorbed into the media.

\section{Fruit production}

Harvesting of ripe fruit began 4 weeks after initiation of the UV-C irradiation treatment. UV-C irradiation of 'Chandler' plants twice a week for 2 months resulted in higher initial cumulative yield of strawberries (Figure 7). The cumulative yield from UV-C treated plants was significantly higher about the midpoint of harvesting period that lasted one month. This increase in yield during this period was a result of more fruit harvested $(+14 \%)$ from UV-C treated plants than due to increase in fruit size. However, at the end of the experiment the cumulative yield, fruit appearance, and percent of small non-marketable fruit (\%) from the UV-C treated and non-treated plants were practically the same.

\section{Biocontrol of strawberry petal infection}

Little infection developed on petals treated with M. pulcherrima and A. pullulans four days after inoculation (Table 2; Figure 8). The tendency toward lower Botrytis infection of petals treated with antagonists continued and was clearly visible even after a 7-day incubation period. All petals inoculated with $B$. cinerea were infected after 7 days, while significantly less $(P \leq 0.05)$ were infected on $M$. pulcherrima and A. pullulans treated petals (e.g., $25 \%$ and $58 \%$ ), respectively.

Effect of UV-C on recovery of antagonist $M$. pulcherrima and $A$. pullulans from strawberry fruit

M. pulcherrima and A. pullulans on NYDA medium are morphologically distinct. M. pulcherrima and A. pullulans developed pinkish and whitish colonies, respectively. In contrast, many filamentous fungi (e.g., Botrytis and Colletotrichum) appear gray- to black-colored. UV-C treatment prior to application of antagonists had no effect on the growth of both yeasts $(P>0.20)$. Similar populations of $M$. pulcherrima as well as A. pullulans were recovered 3 days after spray application from UV-C treated and non-treated fruit (Table 3). More interestingly, dark colonies of filamentous fungi were much abundant on plates with washings from fruit harvested from control plants than from those treated with UV-C alone or in combination with A. pullulans (A1) (Figure 9). Washings from plants treated with UV-C combined with M. pulcherrima (A2) alone or a mixture of the two antagonists $(\mathrm{A} 1+\mathrm{A} 2)$ had mostly lighter colored yeast colonies and dark-colored filamentous fungal colonies were either low or absent. 
TABLE 1. Effects of UV-C exposure time and subsequent dark incubation period on disease severity scores at 3, 6, and 10 days after inoculation (DAI) of detached 'Chandler' strawberry leaves inoculated with Colletotrichum fragariae isolate CF-75 and C. gloeosporioides isolate CG-162. Analysis of variance test was performed on square-root $(y+0.5)$ transformed data.

\begin{tabular}{|c|c|c|c|c|c|c|}
\hline \multirow{3}{*}{$\begin{array}{l}\text { UV-C Exposure } \\
(\min )\end{array}$} & \multicolumn{3}{|c|}{ C. fragariae } & \multicolumn{3}{|c|}{ C. gloeosporioides } \\
\hline & \multicolumn{3}{|c|}{ DAI } & \multicolumn{3}{|c|}{ DAl } \\
\hline & 3 & 6 & 10 & 3 & 6 & 10 \\
\hline 0 & $0.90 \mathrm{a}^{\mathrm{z}}$ & $2.18 a$ & $2.99 a$ & $0.66 \mathrm{a}$ & $1.62 \mathrm{a}$ & $2.44 a$ \\
\hline 1 & $0.66 \mathrm{ab}$ & $1.64 b$ & $2.28 \mathrm{~b}$ & $0.46 a b$ & $1.01 b$ & $1.69 b$ \\
\hline 2 & $0.44 b$ & $1.05 c$ & $1.68 \mathrm{c}$ & $0.42 a b$ & $0.91 b c$ & $1.55 b$ \\
\hline 3 & $0.35 b$ & $1.04 \mathrm{c}$ & $1.66 c$ & $0.31 \mathrm{~b}$ & $0.48 c$ & $1.07 \mathrm{~b}$ \\
\hline LSD & 0.32 & 0.53 & 0.61 & 0.24 & 0.48 & 0.65 \\
\hline \multicolumn{7}{|l|}{$\begin{array}{l}\text { Dark incubation } \\
\text { (hour) }\end{array}$} \\
\hline 0 & $0.42 \mathrm{~b}$ & $1.26 b$ & $1.93 b$ & $0.40 \mathrm{a}$ & $0.85 a$ & $1.51 \mathrm{a}$ \\
\hline 4 & $0.81 a$ & $1.80 \mathrm{a}$ & $2.50 \mathrm{a}$ & $0.59 a$ & $1.24 \mathrm{a}$ & $2.01 a$ \\
\hline 8 & $0.53 b$ & $1.36 \mathrm{ab}$ & $2.01 \mathrm{ab}$ & $0.41 \mathrm{a}$ & $0.95 a$ & $1.57 a$ \\
\hline LSD & 0.27 & 0.46 & 0.53 & 0.21 & 0.41 & 0.56 \\
\hline
\end{tabular}

${ }^{z}$ Different letters in each column and within incubation time and dark period indicate significant difference $(P \leq 0.05)$ based on Fisher's protected least significant difference (LSD).

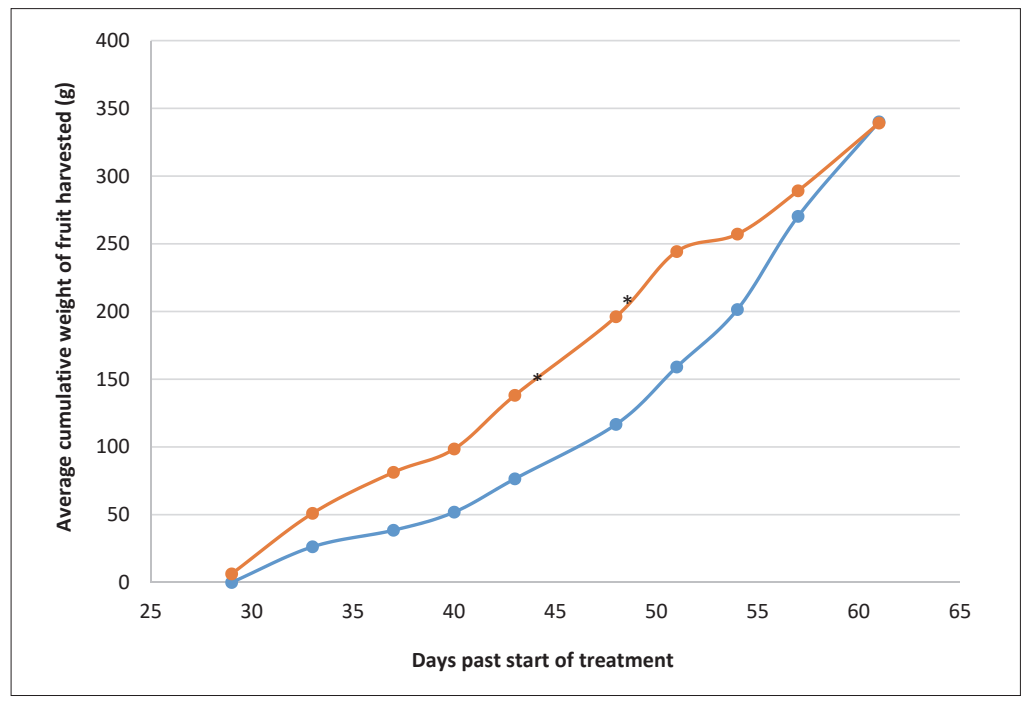

FIGURE 7. Effect of 1-min exposure at night (orange) and no UV-C (blue) on cumulative yield of 'Chandler' strawberry during winter months in a heated greenhouse. Yield data for UV-C plants indicated with an asterisk $\left({ }^{*}\right)$ are significantly different from that of untreated plants, $P=0.05$.
TABLE 2. Incidence of gray mold infection on strawberry flower petals inoculated with Botrytis cinerea and yeast antagonist Aureobasidium pullulans and Metschnikowia pulcherrima. A drop of B. cinerea suspension $\left(1 \times 10^{5}\right.$ conidia $\mathrm{mL}^{-1}$ ) was applied to each petal alone or in combination with antagonist suspensions of M. pulcherrima or A. pullulans. Each petal was inspected for necrotic tissue at 4 and 7 days after inoculation. A drop of water applied to control petals.

\begin{tabular}{lcr}
\hline \multirow{2}{*}{ Treatment } & \multicolumn{2}{c}{ Petals infected (\%) } \\
\cline { 2 - 3 } & Day 4 & Day 7 \\
\hline Control & $0.0 \mathrm{~d}^{\mathrm{z}}$ & $0.0 \mathrm{~d}$ \\
B. cinerea & $83.3 \mathrm{a}$ & $100.0 \mathrm{a}$ \\
B. cinerea + A. pullulans & $41.7 \mathrm{~b}$ & $58.3 \mathrm{~b}$ \\
B. cinerea + M. pulcherrima & $16.7 \mathrm{c}$ & $25.0 \mathrm{c}$ \\
\hline
\end{tabular}

z Mean separation within a column by Duncan-Waller multiple range test at $P=0.05$.
TABLE 3. Recovery of antagonists Aureobasidium pullulans (A1) and Metschnikowia pulcherrima (A2) from the fruit harvested from strawberry plants treated or not-treated twice per week with night-time ultraviolet-C (UV-C) irradiation. Recovery values are expressed as colony forming units $(\mathrm{CFU} \pm \mathrm{SE})$ counted on culture media containing NYDA after 3-day incubation at $25^{\circ} \mathrm{C}$.

\begin{tabular}{lcc}
\hline \multirow{2}{*}{ Treatment } & A1 (A. pullulans) & A2 (M. pulcherrima) \\
\cline { 2 - 3 } & \multicolumn{2}{c}{ CFU g ${ }^{-1}$ strawberry fruit \pm SE $^{*}$} \\
\hline A1 alone & $5.3 \times 10^{4} \pm 5 \times 10^{3}$ & - \\
UV-C + A1 & $4.4 \times 10^{4} \pm 1.4 \times 10^{4}$ & - \\
A2 alone & - & $1.8 \times 10^{5} \pm 2.8 \times 10^{4}$ \\
UV-C + A2 & - & $1.6 \times 10^{5} \pm 3.7 \times 10^{4}$ \\
A1 + A2 & $3.4 \times 10^{4} \pm 7.0 \times 10^{3}$ & $9.0 \times 10^{4} \pm 1.0 \times 10^{4}$ \\
UV-C + A1 + A2 & $3.3 \times 10^{4} \pm 1.8 \times 10^{3}$ & $8.0 \times 10^{4} \pm 1.4 \times 10^{4}$ \\
\hline
\end{tabular}

* Standard error of the mean (SE) of fruit samples collected from 3 replicate plots in a high tunnel strawberry study. 


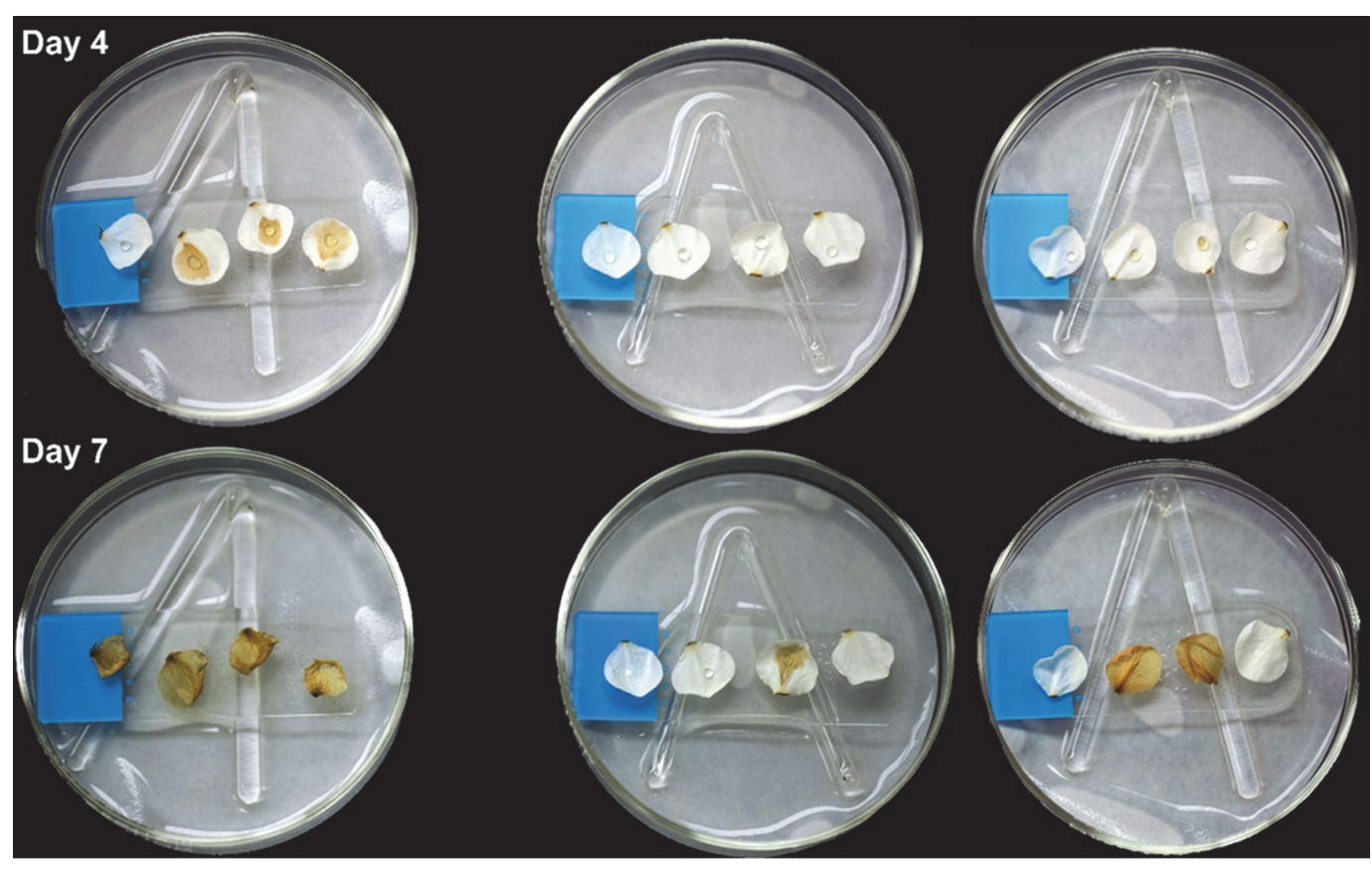

FIGURE 8. Effect of Metschnikowia pulcherrima and Aureobasidium pullulans microbial antagonists on preventing Botrytis

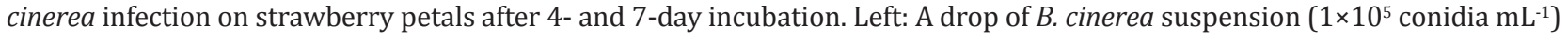
alone. Center: A drop of $B$. cinerea suspension $\left(1 \times 10^{5}\right.$ conidia $\left.\mathrm{mL}^{-1}\right)$ together with $M$. pulcherrima suspension (concentrations adjusted to $50 \%$ transmittance at $420 \mathrm{~nm}$ with a spectrophotometer). Right: A drop of $B$. cinerea suspension $\left(1 \times 10^{5}\right.$ conidia $\mathrm{mL}^{-1}$ ) together with A. pullulans suspension (concentrations adjusted to $50 \% \mathrm{~T}$ at $420 \mathrm{~nm}$ with a spectrophotometer).

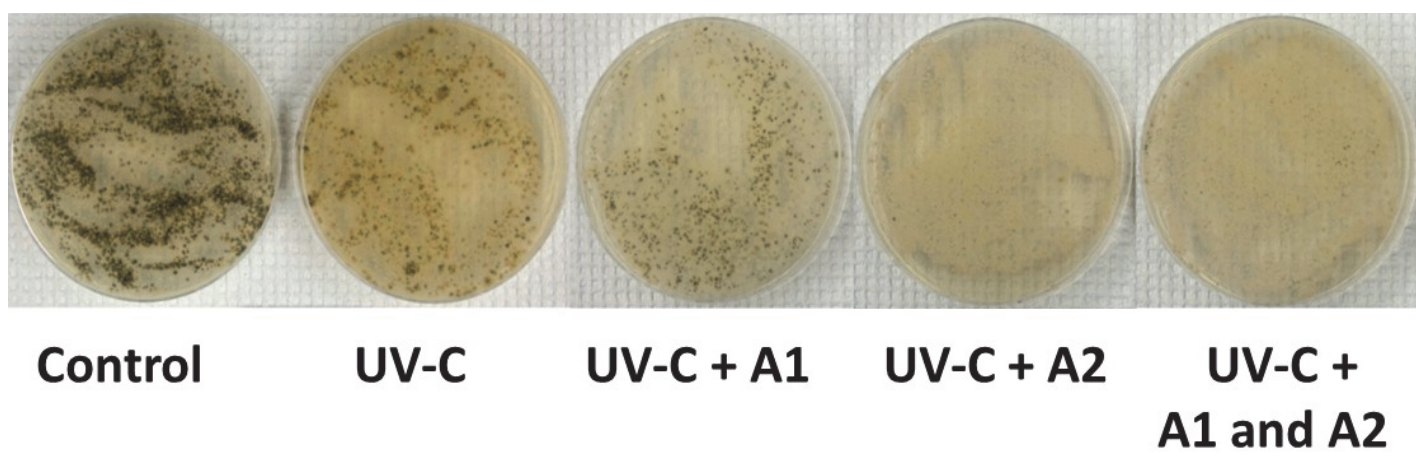

FIGURE 9. Effect of night-time UV-C irradiation alone or with application of microbial antagonists on the abundance of microorganisms recovered from strawberry fruit washings. Left to right: Control, UV-C, UV-C plus Aureobasidium pullulans (A1), UV-C plus Metschnikowia pulcherrima (A2), and UV-C plus A. pullulans and M. pulcherrima. The dark areas indicate the presence of filamentous fungi. The light-colored microbial colonies indicate the presence of yeasts.

\section{Discussion}

Germicidal UV-C (200 - $280 \mathrm{~nm}$ ) lamps have been used in food processing industry to prolong shelf life, preserve nutritional value, and reduce health hazards by sterilizing pathogens and their uses are in compliance with the U.S. Food and Drug Administration safety regulations (Siegner, 2014). However, UV-C treatment of live plants to control diseases and other pests has not been a widely adopted practice because the intensity of the irradiation needed to control pests caused plant toxicity such as leaf scorching and tissue softening (Allende et al., 2006; Van Delm et al., 2014). Additional treatments such as heat or pulsed white light have been tested in combination with UV-C to address low effectiveness of this treatment.
Other methods such as biological and physical control may also be effectively combined with UV-C treatment. These methods of pest control are attractive alternatives to synthetic fungicides as fungicide limitation such as development of resistance in fungi and residue on the fruit has become a growing concern to growers and consumers. Since there are no re-entry restrictions for UV-C irradiation treatments, cultural practices such as plant maintenance or harvesting can begin immediately following UV-C treatment.

UV-C treatment may induce resistance in plants, which may indirectly improve control of various pre- and postharvest pathogens (Janisiewicz et al., 2016b). Janisiewicz et al. (2016a, b) clearly showed that night-time UV-C application followed by a dark period allowed to reduce the dose of UV-C 
irradiation compared to day time treatment without reducing the killing power of the treatment. Maintaining a dark environment after exposure to UV-C light prevents light activation of the DNA repair mechanism in microorganisms (Beggs, 2002). This mechanism most likely contributed to lower levels of UV-C required to kill fungal pathogens (Janisiewicz et al., 2016a). Thus, a 15 to $60 \mathrm{~s}$ UV-C resulting in only 0.0003 to $0.0012 \mathrm{~J} \mathrm{~cm}^{-2}$ dose every 3 to 4 days effectively suppressed infection by $B$. cinerea and $P$. aphanis. Work with UV-B treatments of strawberries and roses also indicated high susceptibility of powdery mildew fungus; however, with this wavelength, treatments of $5 \mathrm{~min}$ to $1 \mathrm{~h}$ were needed to achieve any significant effect (Kanto et al., 2009; Suthaparan et al., 2012). These long exposure times led to noticeable phytotoxic effects. The reduction in the exposure time achieved with night-time UV-C treatments decreases the energy cost and permits the mobile platform to cover a much larger area, making this approach commercially feasible.

UV-C treatment at night resulted in a dramatic increase in kill of B. cinerea and P. aphanis (Janisiewicz et al., 2016a, b). Postharvest treatments of strawberries with UV-C apparently induces resistance to decay-causing fungi resulting in reduction in decay (Jin et al., 2017; Pombo et al., 2011), adding another layer of protection against pathogens. Our findings suggest that $C$. fragariae and $C$. gloeosporioides can be controlled with UV-C irradiation alone. Even with night-time treatment at 3- to 4-day intervals, low dose of UV-C $(1.2 \mathrm{~mJ}$ $\mathrm{cm}^{-2}$ ), which is below the levels resulting in plant toxicity, was effective in killing fungal conidia or making them not infectious. UV-C irradiation kills a significant part of the microbial population on the plant surface. This is clearly visible by comparing abundance of dark colonies representing filamentous fungi on plates seeded with washings from UV-C treated and non-treated fruit (Figure 9). This creates a microbial "vacuum," resulting in a lack of competition from the natural microbial populations to newly arriving airborne conidia of pathogens.

Introduction of microbial antagonists is an excellent strategy to occupy the empty niches that were created by UV-C treatment and to prevent re-colonization by unwanted taxa, either human or plant pathogens. The two antagonists evaluated in this study were efficient colonizers of plant parts and quickly filled in the microbial void resulting from the UV-C treatment. We demonstrated that introduction of two microbial antagonists resulted in efficient recolonization of the fruit surface after UV-C treatment. On strawberry flower petals $M$. pulcherrima provided a better biocontrol of $B$. cinerea than A. pullulans.

During the last decade in the southeastern United States and California, there have been reports about loss of efficacy of fungicides for controlling $\mathrm{B}$. cinerea as well as $\mathrm{Col}$ letotrichum species (Hu et al., 2017; Pokorny et al., 2016). Colletotrichum spp. cause anthracnose fruit rot and crown rot with infection most often observed when conditions are warm and wet (Poling, 2008). Both of these fungal pathogens now have developed resistance to multiple chemical classes of fungicides, particularly the widely used strobilurin fungicides [active ingredient axoxystrobin in Abound (Syngenta Corp., Greensboro, NC, USA) and pyraclostrobin in Pristine (BASF Corp., Florham Park, NJ, USA)]. In vitro assays clearly showed the efficacy of our UV-C irradiation treatment followed by a dark period against Colletotrichum species. UV-C irradiation treatment kept the disease severity score of 'Chandler' strawberry leaves inoculated with $C$. fragariae and $C$. gloeosporioides to less than 2 for six days (Table 1). In
USDA germplasm selection trials for anthracnose resistance, plants with a DSR score of $\leq 2.0$ is considered resistant, those of with a DSR of 2.0 to 4.0 are considered intermediate (Miller-Butler et al., 2013; Smith and Black, 1990). However, onetime treatment of anthracnose-infected leaves with UV-C irradiation was not sufficient in completely suppressing the invasion of leaf mesophyll tissues by C. fragariae or C. gloeosporioides. The difference in leaf disease severity scores among the three dark treatments of leaves inoculated with isolate C. gloeosporioides was not significant. These findings were different from the results obtained from in vitro studies. It is possible that the fungus had already penetrated into the mesophyll of the leaf when the UV-C irradiation treatment was applied. Curry et al. (2002) had previously reported that the appressorium of $C$. fragariae can penetrate through the cuticle and hyphal growth occurs in sub-epidermal tissues in less than $24 \mathrm{~h}$. More trials are necessary to achieve higher level of anthracnose disease control with UV-C irradiation. The invasion of strawberry plants by Colletotrichum species can occur rapidly therefore frequent, multiple UV-C irradiation treatments of strawberry plants appear to be necessary.

Previous work with ornamental crops showed that high UV-C irradiance levels $\left(>0.5 \mathrm{KJ} \mathrm{m}^{-2}\right)$ increased branch numbers and accelerated flowering (Bridgen, 2016; Darras et al., 2013). The results of our work suggest that even relatively low irradiance levels $\left(12 \mathrm{~J} \mathrm{~m}^{-2}\right)$ and short-term exposure (e.g., $60 \mathrm{~s})$ during night can affect the reproductive development (e.g., flower production in short-day 'Chandler' strawberry). Recently, we reported that night-time UV-C irradiation also reduced Tetranychus urticae mite populations on strawberry plants (Short et al., unpublished data). Enhancing the early yield and a non-chemical control of two-spotted spider mite are other benefits of UV-C irradiation technology that could lead to more sustainable and environmentally friendly strawberry production practices.

\section{Conclusions}

Our approach to treating strawberry plants over the entire season twice a week with UV-C for $60 \mathrm{~s}$ at night followed by a defined dark period represents a significant advancement in use of UV-C as a feasible control treatment for commercial applications to control several pathogens (B. cinerea, P. aphanis, and Colletotrichum spp.). This treatment has no negative effects on plant photosynthetic rate, pollen viability, pollen tube growth, or fruit set and development (Janisiewicz et al., 2016a). Also, our previous work (Janisiewicz et al., 2016b) on the effects of UV-C irradiation on the strawberry plants infected with powdery mildew showed that the UV-C treatment had no effect on gas exchange of strawberry plants. The photosynthetic rate $\left(19.1 \mu \mathrm{mol} \mathrm{m}^{-2} \mathrm{~s}^{-1}\right)$, transpiration $\left(2.5 \mu \mathrm{mol} \mathrm{m}{ }^{-2} \mathrm{~s}^{-1}\right)$, and photosynthesis/transpiration ratio $(\mu \mathrm{mol} / \mu \mathrm{mol})$ of UV-C treated plants were not significantly different from those of the healthy plants. Combining biological control with the non-fungicide aspects of the IPM system such as this UV-C treatment for disease control appears to be a logical approach for developing a sustainable strawberry growing system for producing fruit that is free of pesticide residues. Our new technology that combines UV-C irradiation followed by a dark period and antagonist application starting early after planting addresses many concerns for currently used strawberry production practices in both indoor and field production. 


\section{Acknowledgments}

Technical support from Scott Wolford, Ann Rose, Wade Snyder, and Melinda Miller-Butler is greatly appreciated.

\section{References}

Allende, A., McEvoy, J.L., Luo, Y., Artes, F., and Wang, C.Y. (2006). Effectiveness of two-sided UV-C treatments in inhibiting natural microflora and extending the shelf-life of minimally processed 'Red Oak Leaf' lettuce. Food Microbiol. 23, 241-249. https://doi. org/10.1016/j.fm.2005.04.009.

Beggs, C.B. (2002). A quantitative method for evaluating the photoreactivation of ultraviolet damaged microorganism. Photochem. Photobiol. Sci. 1, 431-437. https://doi.org/10.1039/ b202801h.

Bridgen, M.P. (2016). Using ultraviolet-C (UV-C) irradiation on greenhouse ornamental plants for growth regulation. Acta Hortic. 1134, 49-56. https://doi.org/10.17660/ActaHortic.2016.1134.7.

Bulger, M.A., Ellis, M.A., and Madden, L.V. (1987). Influence of temperature and wetness duration on infection of strawberry flowers by Botrytis cinerea and disease incidence of fruit originating from infected flowers. Phytopathology 77, 1225-1230. https://doi. org/10.1094/Phyto-77-1225.

Burr, T.J., Schroth, M.N., and Suslow, T. (1978). Increased potato yields by treatment of seed pieces with specific strains of Pseudomonas fluorescens and P. putida. Phytopathology 68, 1377-1383. https:// doi.org/10.1094/Phyto-68-1377.

Chang, P., and Smith, B.J. (2007). Response of 'Treasure' and 22 Florida strawberry genotypes to the anthracnose pathogens Colletotrichum acutatum, C. fragariae, and C. gloeosporioides. In Proc. 2007, N. American Strawberry Symposium, F. Takeda, D.T. Handley, and E.B. Poling, eds. (Kemptville, ON, Canada: North American Strawberry Growers Assoc.), p. 69-73.

Cook, J.R., and Baker, K.F. (1983). The Nature and Practice of Biological Control of Plant Pathogens (St. Paul, MN: Amer. Phytopathology Soc.).

Curry, K.J., Abril, M., Avant, J.B., and Smith, B.J. (2002). Strawberry anthracnose: Histopathology of Colletotrichum acutatum and $C$. fragariae. Phytopathology 92, 1055-1063. https://doi.org/10.1094/ PHYT0.2002.92.10.1055.

Darras, A.K., Demopoulos, V., Bali, I., Katsiloulis, V., and Kratimenou, E. (2013). Brief exposure to ultraviolet-C (UV-C) irradiation improves flowering of ornamental plants. Acta Hortic. 1002, 95-101. https:// doi.org/10.17660/ActaHortic.2013.1002.10.

Demchak, K. (2013). The Mid-Atlantic Berry Guide (University Park, PA: Pennsylvania State University Extension).

Dimitri, C., and Greene, C. (2002). Recent Growth Patterns in the U.S. Organic Foods Market. In USDA-ERS Agriculture Information Bull. No. 777 (Washington, D.C.: USDA ERS). https://www.ers.usda.gov/ webdocs/publications/42455/12915_aib777_1_.pdf?v=41055.

Fernández-Ortuño, D., Grabke, A., Li, X., and Schnabel, G. (2015). Independent emergence of resistance to seven chemical classes of fungicides in Botrytis cinerea. Phytopathology 105, 424-432. https://doi.org/10.1094/PHYTO-06-14-0161-R.

Hu, M.-J., Cox, K.D., and Schnabel, G. (2016). Resistance to increasing chemical classes of fungicides by virtue of "Selection by Association" in Botrytis cinerea. Phytopathology 106, 1513-1520. https://doi. org/10.1094/PHYTO-04-16-0161-R.

Janisiewicz, W.J., and Conway, W.S. (2011). Combining biological control with physical and chemical treatments to control fruit decays after harvest. Steward Postharv. Rev. 9, 1-16.
Janisiewicz, W.J., Takeda, F., Glenn, D.M., Camp, M.J., and Jurick, W.M. (2016a). Dark period following UV-C treatment enhances killing of Botrytis cinerea conidia and controls gray. Phytopathology 106, 386394. https://doi.org/10.1094/PHYTO-09-15-0240-R.

Janisiewicz, W.J., Takeda, F., Nichols, B., Glenn, D.M., Jurick, W.M., and Camp, M.J. (2016b). Use of low-dose UV-C irradiation to control powdery mildew caused by Podosphaera aphanis on strawberry plants. Can. J. Plant Path. 38, 430-439. https://doi.org/10.1080/07 060661.2016.1263807.

Jin, P., Wang, H., Zhang, Y., Huang, Y., Wang, L., and Zheng, Y. (2017). UV-C enhances resistance against gray mold decay caused by Botrytis cinerea in strawberry fruit. Sci. Hortic. 225, 106-111. https://doi. org/10.1016/j.scienta.2017.06.062.

Kanto, T., Matsuura, K., Yamada, M., Usami, T., and Amemiya, Y. (2009). UV-B radiation for control of strawberry powdery mildew. Acta Hortic. 842, 359-362. https://doi.org/10.17660/ ActaHortic.2009.842.68.

Kretschmer, M., Leroch, M., Mosbach, A., Walker, A.-S., Fillinger, S., Mernke, D., Schoonbeek, H.-J., Pradier, J.-M., Leroux, P., De Waard, M.A., and Mathias, H. (2009). Fungicide-driven evolution and molecular basis of multidrug resistance in field populations of the grey mould fungus Botrytis cinerea. PLOS Pathogens 5, 1-13. https:// doi.org/10.1371/journal.ppat.1000696.

Lamichhane, J.R., Dachbrodt-Saaydeh, S., Kudsk, P., and Messean, A. (2016). Toward a reduced reliance on conventional pesticides in European agriculture. Plant Dis. 100, 10-24. https://doi. org/10.1094/PDIS-05-15-0574-FE.

Miller-Butler, M.A., Curry, K.J., Kreiser, B.R., and Smith, B.J. (2013). Visual and electronic evaluations of detached strawberry leaves inoculated with Colletotrichum species. Int. J. Fruit Sci. 13, 114-125. https://doi.org/10.1080/15538362.2012.697033.

Oliveira, M.S., Amiri, A., Zuniga, A.I., and Peres, N.A. (2017). Sources of primary inoculum of Botrytis cinerea and their impact on fungicide resistance development in commercial strawberry fields. Plant Dis. 101,1769-1773. https://doi.org/10.1094/PDIS-02-17-0203-RE.

Pavan, W., Fraisse, C.W., and Peres, N.A. (2012). The Strawberry Advisory System: A web-based decision support tool for timing fungicide applications in strawberry (Gainesville, FL: Institute of Food and Agricultural Sciences, University of Florida). https://edis. ifas.ufl.edu/pdffiles/AE/AE45000.pdf.

Pokorny, A., Smilanick, J., Xiao, C.-L., Forrar, J.J., and Shrestha, A. (2016). Determination of fungicide resistance in Botrytis cinerea from strawberry in the central costal region of California. Plant Health Progr. 17, 30-34. https://doi.org/10.1094/PHP-RS-15-0053.

Poling, E.B. (2008). Anthracnose on strawberry: Its etiology, epidemiology, and pathology, together with management strategies for strawberry nurseries: Introduction to the Workshop. HortScience $43,59-65$.

Pombo, M.A., Rosli, H.G., Martinez, G.A., and Civello, P.M. (2011). UV-C treatment affects the expression and activity of defense genes in strawberry fruit (Fragaria $\times$ ananassa Duch.). Postharvest Biol. Technol. 59, 94-102. https://doi.org/10.1016/j. postharvbio.2010.08.003.

Siegner, C. (2014). Does ultraviolet mean ultrasafe? Food Safety News (Jan. 27). http://www.foodsafetynews.com/2014/01/ pasteurization-does-ultraviolet-mean-ultrasafe/\#.WfxyQU0Unct.

Smith, B.J., and Black, L.L. (1990). Morphological, cultural, and pathogenic variation among Colletotrichum species isolated from strawberry. Plant Dis. 74, 69-76. https://doi.org/10.1094/PD-740069 . 
Strand, L. (2008). Integrated Pest Management for Strawberries, $2^{\text {nd }}$ ed. (Oakland, CA: University of California).

Suthaparan, A., Stensvand, A., Solhaug, K.A., Torre, S., Mortensen, L.M., Gadoury, D.M., Seem, R.C., and Gislerød, H.R. (2012). Suppression of powdery mildew (Podosphaera pannosa) in greenhouse roses by brief exposure to supplemental UV-B radiation. Plant Dis. 96, 16531660. https://doi.org/10.1094/PDIS-01-12-0094-RE.

Sylla, J., Alsanius, B.W., Kruger, E., Becker, D., and Wohanka, W. (2013). In vitro compatibility of microbial agents for simultaneous application to control strawberry powdery mildew (Podosphaera aphanis). Crop Prot. 51, 40-47. https://doi.org/10.1016/j. cropro.2013.04.011.

Van Delm, T., Melis, P., Stoffels, K., and Beats, W. (2014). Control of powdery mildew by UV-C treatment in commercial strawberry production. Acta Hortic. 1049, 679-684. https://doi.org/10.17660/ ActaHortic.2014.1049.105.

Received: Dec. 5, 2017

Accepted: Apr. 20, 2018

Addresses of authors:

Fumiomi Takeda ${ }^{1, *}$, Wojciech J. Janisiewicz ${ }^{1}$,

Barbara J. Smith ${ }^{2}$ and Breyn Nichols ${ }^{1}$

${ }^{1}$ USDA Agricultural Research Service, Appalachian Fruit Research Station, 2217 Wiltshire Road, Kearneysville, WV, 25430, USA

${ }^{2}$ USDA Agricultural Research Service, Thad Cochran Southern Horticultural Laboratory, 810 Highway 26, Poplarville, MS, 39470, USA

* Corresponding author; E-mail: fumi.takeda@ars.usda.gov 